\title{
RASTREAMENTO, NOTIFICAÇÃO E IMPLEMENTAÇÃO DE AÇÕES DE VIGILÂNCIA RELACIONADAS À TRANSMISSÃO VERTICAL DE HEPATITE B
}

Juliana Balbinot Reis Girondi ${ }^{1}$, Elizimara Ferreira Siqueira ${ }^{2}$, Jaques da Silva ${ }^{3}$, Jezabel Andrade Silva ${ }^{4}$, Janelice de Azevedo Neves Bastiani ${ }^{5}$

\begin{abstract}
RESUMO: O artigo trata da descrição de um caso de transmissão vertical de hepatite B com ênfase em aspectos relacionados à vigilância epidemiológica: rastreamento, notificação e implementação de ações de vigilância. Este caso clínico mostra a prevalência da doença na gestação e parto, já que três gerações de uma família se contaminaram, provavelmente pela transmissão vertical. O controle da doença é realizado por meio de rastreamento do antígeno de superfície do VHB (AgHBS) em gestantes e vacinação de rotina. É função da Vigilância Epidemiológica e do Programa de Saúde da Família (PSF) adotar medidas de controle específicas para hepatite. É necessário esclarecer a comunidade quanto às formas de transmissão, tratamento e prevenção das hepatites virais. Entendemos nossas limitações ao abordar o tema, mas esperamos incitar em outros profissionais o interesse e a prática destas ações tão importantes, já que se implementadas de forma efetiva melhoraram a qualidade de vida da população.
\end{abstract}

PALAVRAS-CHAVE: Hepatite B; Vigilância Epidemiológica; Transmissão.

\section{INVESTIGATION, NOTIFICATION AND IMPLEMENTATION OF VIGILANCE ACTIONS RELATED TO VERTICAL TRANSMISSION OF HEPATITIS B}

ABSTRACT: The present article reports a case of vertical transmission of hepatitis B stressing aspects related to epidemiologic vigilance: investigation, notification and implementation of diligence actions. The present clinical case presents the prevalence of the disease during pregnancy and delivery, since three generations of the same family were contaminated, probably, through vertical transmission. The disease control happens via investigation of HBV surface antigen (HBsAg) in pregnant women and via routine vaccination. It is the Epidemiologic Surveillance and the Family Health Program (FHP)'s duty to adopt specific hepatitis control measures. It is necessary to make it clear to the community the ways the disease is transmitted, treatment and prevention of viral hepatitis. We understand our limitations when approaching the theme, but we expect to stimulate the interest and practice of such important actions in other professionals, because if these actions are implemented in an effective way, they tend to improve population's quality of life.

KEYWORDS: Hepatitis B, Epidemiologic Surveillance, Transmission.

\section{INVESTIGACIÓN, NOTIFICACIÓN Y REALIZACIÓN DE ACCIONES DE VIGILANCIA RELACIONADAS CON TRANSMISIÓN VERTICAL DE HEPATITIS B}

RESÚMEN: El artículo presente hace un informe de un caso de transmisión vertical de la hepatitis B enfocando aspectos relacionados con la vigilancia epidemiologica: investigación, notificación y realización de acciones de diligencia. El caso clínico del estudio presenta el predominio de la enfermedad durante embarazo y parto, ya que tres generaciones de la misma familia fueron contaminadas, probablemente, por la transmisión vertical. El control de la enfermedad es realizado por medio de investigación del antígeno de la superfície del VHB (AgHBS) en mujeres embarazadas y la vacunación de rutina. Es función de la Vigilancia Epidemiologica y del Programa de la Salud de Familia (PSF) adoptar medidas de control específicas para la hepatitis. Es necesario aclarar a la sociedad acerca de los caminos por los cuales la enfermedad es transmitida, el tratamiento de la enfermedad, y la prevención de la hepatitis viral. Entendemos nuestras limitaciones acercándonos al tema, pero esperamos estimular el interés y la práctica de tales acciones importantes porque si estas acciones son puestas en práctica de un modo eficaz, es posible mejorar la calidad de vida de la población.

PALABRAS-CLAVE: Hepatitis B; Vigilancia epidemiológica; Transmisión.

\footnotetext{
${ }^{1}$ Enfermeira Supervisora em Saúde da Regional Continente de Saúde (PSF), Florianópolis. Enfermeira do Hospital Universitário-HU, Florianópolis. Doutoranda em Enfermagem pela Universidade Federal de Santa Catarina-UFSC.

${ }^{2}$ Enfermeira Coordenadora da Regional Continente de Saúde(PSF), Florianópolis.

${ }^{3}$ Enfermeira da Regional Continente de Saúde (PSF), Florianópolis.Docente do Curso de Graduação em Enfermagem da Universidade do Vale do Itajaí-Univali.

${ }^{4}$ Técnico em Enfermagem da Vigilância Epidemiológica da Regional Continente de Saúde(PSF), Florianópolis

${ }^{5}$ Enfermeira Assessora da Vigilância Epidemiológica da Regional Continente de Saúde(PSF), Florianópolis.
}

Autor correspondente:

Juliana Balbinot Reis Girondi

Rua Delminda Silveira, 363 - 88025-500 - Florianópolis-SC

Recebido: 02/03/08

E-mail: julibreis@hotmail.com

Aprovado: 06/05/08 


\section{INTRODUÇÃO}

Dentre as doenças endêmico-epidêmicas notificadas no Brasil destacam-se as hepatites virais, cujo comportamento epidemiológico tem sofrido grandes mudanças nos últimos anos, o que elevou o número de notificações de casos suspeitos.

As hepatites são doenças provocadas por tipos de vírus que tem tropismo pelo fígado. Considerada uma doença sexualmente transmissível, age de forma silenciosa com distintas características epidemiológicas, de evolução clínica, imunológicas e laboratoriais. A distribuição das diversas formas de hepatite é heterogênea em todo mundo.

No Brasil na Região Norte, no Espírito Santo e no Oeste de Santa Catarina a maior prevalência é a de hepatite $\mathrm{B}^{(1)}$. Na região norte, estas condições estariam relacionadas à promiscuidade domiciliar $\mathrm{e}$ as más condições higiênicas e sanitárias, gerando um padrão epidemiológico em que os indivíduos são infectados pelo vírus da hepatite B (HBV) precocemente. Na região sul, especificamente no estado de Santa Catarina, esta relação seria em virtude da pluralidade étnica ${ }^{(2)}$.

O homem é o único reservatório com importância epidemiológica. A hepatite $\mathrm{E}$ ainda admite alguns outros reservatórios como porco, macaco e ratões. Estão sendo realizadas pesquisas a esse respeito para que se tenha a comprovação. A transmissibilidade varia de acordo com o agente etiológico. Os vírus das hepatites B, C e D são transmitidos por via parenteral e os da hepatite B também podem ter transmissão sexual e vertical (mãefilho); enquanto que as hepatites A e E têm transmissão fecal-oral. No caso da hepatite $B$, o número de pessoas portadoras desta patologia vem aumentando consideravelmente nas últimas décadas. O que torna este problema alarmante é o fato de que a maioria das pessoas desconhece seu estado de portador e constitui um elo importante na cadeia de transmissão do $\mathrm{HBV}^{(3)}$.

No Brasil, de 1996 a 2000, a hepatite B foi o segundo tipo mais prevalente (25\%), tendo sido a hepatite A, líder em casos (43\%). Em Santa Catarina houve predomínio de Hepatite $\mathrm{B}$ em relação às outras hepatites de 1997 a 2001. A maior incidência foi observada na faixa etária dos 20 aos 49 anos para Santa Catarina e acima dos 30 anos para o Brasil( ${ }^{(4-6)}$.

O diagnóstico da hepatite basicamente é feito por exames laboratoriais inespecíficos que podem indicar agressão hepática, provavelmente causada pelos agentes das hepatites virais; porém, o agente etiológico só poderá ser confirmado com exames específicos, por meio de testes sorológicos. A sintomatologia da doença pode ou não estar presente. Quando isso ocorre, os principais sintomas são: mal-estar, cefaléia, febre baixa, anorexia, astenia, fadiga, artralgia, náuseas, vômitos, prurido corporal, desconforto abdominal na região do fígado e aversão a alguns alimentos e cigarro. A icterícia geralmente se inicia quando a febre desaparece e pode ser precedida por colúria e hipocolia fecal. A hepatomegalia ou a hepatoesplenomegalia também pode se apresentar como sintoma.

Em decorrência do exposto, e pelas escassas referências encontradas na literatura no que se relaciona à deficiência de diagnóstico materno de Hepatite B, realizamos um estudo de caso para respaldar nossas preocupações em relação ao impacto desta doença na qualidade de vida/doença da população em geral. Assim, este artigo descreve um caso de transmissão vertical de hepatite B e busca refletir sobre aspectos gerais e as intervenções específicas de rastreamento, notificação e implementação de ações de vigilância.

\section{HEPATITE B E A TRANSMISSÃO VERTICAL}

A infecção materno-infantil (vertical) e horizontal nos primeiros anos de vida ocorre em regiões de alta endemicidade como África, China e Sudeste Asiático. Na Europa, EUA e Austrália, a contaminação ocorre na vida adulta, principalmente em grupos de risco acrescido, que possuem baixa endemicidade da doença. No Brasil, ocorre alta endemicidade na região Amazônica, Espírito Santo e oeste de Santa Catarina, endemicidade intermediária nas regiões Centro-Oeste, Nordeste e Sudeste e baixa endemicidade na região $\mathrm{Sul}^{(7)}$.

$\mathrm{O}$ vírus da hepatite $\mathrm{B}$ (HBV) é transmitido por meio de lesões na pele e mucosa, relações sexuais, via parenteral, transmissão perinatal e/ou nos contatos domiciliares em ambientes superlotados. Os fômites são importantes na cadeia epidemiológica de transmissão, como barbeadores, agulhas, alicates de unha, escovas de dente, lixa de unhas, objetos de uso pessoal constituindo-se em reservatórios ideais para o vírus ${ }^{(8)}$.

No Brasil, antes de 1992, os bancos de sangue não possuíam controle de qualidade nas bolsas de sangue dos doadores, acarretando um grande número de transmissão do vírus nas transfusões sanguíneas. Todas estas situações de exposição são situações de risco às pessoas, mas não se deve esquecer que 
seringas, cachimbos e canudos para aspiração de drogas, tatuagens, acupuntura e colocação de piercing devem ser descartáveis ${ }^{(8)}$.

A infecção pelo vírus da hepatite B (HBV) que ocorre na infância, adquirida da mãe portadora desse virus, representa $40 \%$ do total de infecções e possui grande relevância clínica e epidemiológica em todo mundo. Apesar de a infecção aguda ser sintomática em menos de $10 \%$ das crianças, o desenvolvimento da infecção crônica e de suas conseqüências, após a infecção aguda, é inversamente proporcional à idade da exposição. $\mathrm{O}$ risco de infecção crônica é máximo (70-90\%) em crianças que adquirem a infecção durante o período perinatal, sendo que constituirão o principal reservatório do vírus para infecção de outros indivíduos ${ }^{(9)}$.

A transmissão do HBV da mãe portadora para o seu filho pode ocorrer no período gestacional. No entanto, a exposição perinatal ao sangue e secreções genitais maternas é o modo mais eficiente de transmissão, podendo acometer de 65 a 93\% dos recém nascidos de mães infectadas e portadoras de HBeAg, sendo menor o risco de infecção (0 a 19\%) na ausência desse marcador ${ }^{(9)}$.

Nas mulheres grávidas, expostas à doença, há grandes chances do recém nascido sofrer lesão irreversível do fígado: já nos adultos expostos, a lesão freqüentemente se transforma em um câncer. Os casos crônicos de hepatite B correspondem em torno de $1 \%$ da população acometida de cirrose e câncer de fígado ${ }^{(3)}$.

Atualmente, existem poucos estudos que abordam o rastreamento de hepatite B em gestante. Assim, a associação da hepatite viral aguda e gravidez é pouco freqüente, já que na maioria dos casos, ela apresenta-se de forma assintomática ou com sinais e sintomas inespecíficos, por vezes confundindo-se com distúrbios fisiológicos comuns da própria gravidez. Por isso, muitas mulheres com HBV assintomáticas são identificadas de forma indireta a partir de um achado de altas taxas de transaminases ${ }^{(10)}$.

\section{METODOLOGIA}

Trata-se de um estudo de caso de transmissão vertical de hepatite $\mathrm{B}$ ocorrido em três gerações numa família proveniente de um município do meio oeste catarinense e residente atualmente no município de Florianópolis. A escolha por esse método exploratório e qualitativo, ocorreu por ser um estudo de fácil aplicabilidade e baixo custo, possibilitando a descrição de um caso a partir da observação de poucos indivíduos, utilizando para coleta de dados as fichas de investigação epidemiológica e exames laboratoriais.

Normalmente, todas as etapas da investigação epidemiológica devem ser percorridas para que seus objetivos sejam atingidos; no entanto, em muitas ocasiões há simultaneidade entre algumas delas. Além disso, é muito comum, com o avanço da investigação, retornar para etapas anteriores, revendo-as à luz de novos dados ou enriquecendo-as com informações mais consistentes ${ }^{(11)}$.

Os sujeitos deste estudo foram seis membros de uma família proveniente de um município do meio oeste catarinense e residente atualmente no município de Florianópolis.

Para preservar o sigilo de identificação dos pacientes envolvidos na descrição do caso, utilizaremos as iniciais de seus nomes e graus de parentesco.

\section{Etapas da investigação epidemiológica}

A investigação epidemiológica realizada neste estudo de caso seguiu algumas etapas, as quais são apresentadas a seguir.

\section{Primeira Etapa: Confirmar a existência do caso}

A primeira intervenção da vigilância epidemiológica ao receber uma ficha de Notificação de Agravo é levantar dados para fornecer informações sobre o possível caso.

\section{Segunda Etapa: Verificar o diagnóstico}

Esta etapa é a confirmação laboratorial do diagnóstico, afastando eventuais erros de notificação e laboratoriais. Se os dados do laboratório são inconsistentes com os achados clínicos, as técnicas laboratoriais devem ser revistas ${ }^{(11)}$.

\section{Terceira Etapa: Definir caso e identificar contatos}

Entende-se por definição de caso, a padronização de um conjunto de critérios, com o objetivo de decidir se um determinado paciente deve ser classificado como caso, com referência à condição de interesse à investigação. A definição de caso inclui critérios clínicos (sinais e sintomas), laboratoriais e epidemiológicos; estes 
últimos devem sempre considerar um conjunto de restrições relativas ao tempo, espaço e pessoa, decorrentes da investigação ${ }^{(11)}$.

O levantamento de dados efetuados durante a investigação de um caso de hepatite é importante na identificação dos contatos domiciliares e sexuais, neste estudo especificamente, os contatos domiciliares, por se tratar de hepatite B. É importante a ampla divulgação entre profissionais de saúde sobre estas informações, a fim de que estejam atentos para detecção precoce de possíveis novos casos.

\section{Quarta Etapa: Analisar os dados disponíveis}

Nesta etapa, a análise dos dados disponíveis deve ser efetuada de maneira que possam ser elaboradas hipóteses com vistas à identificação das fontes e modos de transmissão. Com esse objetivo, informações coletadas devem ser organizadas de forma a responder questões relativas ao tempo, lugar e pessoa.

\section{Quinta Etapa: Desenvolver hipóteses}

Concluídos todos os procedimentos de análise dos dados levantados durante a investigação epidemiológica, o próximo passo é a formulação de hipóteses. Estas devem estar voltadas à identificação da fonte de infecção, modos de transmissão e tipos de exposição associadas ao risco de adoecer. Podemos gerar hipótese de diferentes maneiras, porém as mais utilizadas levam em consideração o conhecimento científico disponível e a descrição minuciosa da doença na busca de diferenciais de risco, segundo variáveis relativas ao tempo, espaço e pessoa ${ }^{(11)}$.

\section{Sexta Etapa: Testar hipóteses}

Nas investigações epidemiológicas de campo podem ser testadas hipóteses, fundamentalmente, de duas maneiras: a) comparando as hipóteses com os fatos, quando estes já se apresentam bem estabelecidos; b) aplicando a metodologia epidemiológica analítica, com objetivo de quantificar as associações e explorar o papel do aleatório nessas associações ${ }^{(11)}$.

\section{Sétima Etapa: Avaliar medidas de prevenção $e$ controle}

Após investigação do caso, as ações de vigilância epidemiológica apresentam características que tornam indispensáveis a aplicação, tão rápido quanto possível, de medidas de controle. Isso muitas vezes ocorre antes mesmo de identificarmos, perfeitamente, as fontes de infecção e os modos de transmissão, utilizando, num primeiro momento, tão somente os resultados preliminares da investigação ${ }^{(11)}$.

\section{Oitava Etapa: Comunicar a todos os interessados os resultados}

Esta é a forma de disseminar os conhecimentos produzidos a partir de uma análise abrangendo todas as etapas da investigação, inclusive aqueles resultantes das pesquisas por ela induzidas. Esse procedimento cria um elo de ligação entre os serviços de saúde e a produção do conhecimento, estabelecendo condições para o contínuo aperfeiçoamento da assistência à saúde ${ }^{(11)}$.

Cabe à equipe da vigilância epidemiológica comunicar o paciente e/ou contatos sobre resultados dos exames; agendamento do caso para nova coleta de controle de exames (após seis meses); vacinação dos contatos (quando necessário); comunicar a equipe de Saúde da Família da área de abrangência do caso e proceder a retroalimentação dos dados no Sistema Nacional de Agravos de Notificação (SINAN).

Normalmente, todas as etapas da investigação devem ser percorridas para que seus objetivos sejam atingidos; no entanto, em muitas ocasiões há simultaneidade entre algumas delas. Além disso, é muito comum, com o avanço da investigação, retornar para etapas anteriores, revendo-as à luz de novos dados ou enriquecendo-as com informações mais consistentes $^{(11)}$.

\section{DESCRIÇÃO DO CASO}

A Vigilância Epidemiológica foi notificada de um caso suspeito de Hepatite B ( $1^{\circ}$ trimestre de 2007). Tratava-se de uma criança com sete anos de idade, chamada PMP, sexo feminino, acompanhada num Centro de Saúde da periferia de Florianópolis (SC), pela equipe do Programa Saúde da Família (PSF), em consultas de pediatria. A paciente apresentava os seguintes exames sorológicos: HCV negativo e AgHBs positivo e sintomatologia: febre, inapetência, astenia, prurido corporal, cefaléia e náuseas.

A partir da notificação do caso pela unidade local de saúde a equipe da Vigilância Epidemiológica, de uma Regional de Saúde, iniciou a investigação do provável caso índice e rastreamento de doentes- 
portadores da doença no ambiente domiciliar. Tal atividade é desenvolvida pela equipe da Vigilância Epidemiológica que atua orientando os profissionais de saúde sobre ações de investigação epidemiológica e medidas de prevenção e controle das doenças transmissíveis. Dessa forma, é possível melhorar a condição de saúde da população pela eliminação e/ou atenuação dos riscos associados à rápida disseminação com grande impacto sobre a morbimortalidade que a mesma apresenta. Pela investigação do caso foi "suspeitado" transmissão vertical, por meio da coleta de marcadores sorológicos e seus respectivos resultados em contatos domiciliares. Os contatos de PMP: pai (LP) AgHBs negativo e mãe (FMP) AgHBs positivo, sendo que a avó materna (MTM) apresentava AgHBs positivo e avô materno (SRPM) não foi coletado amostra, pois o mesmo encontrava-se no município de residência. Como parte da família é residente em um município do meio oeste catarinense, houve dificuldades na coleta de dados durante a investigação epidemiológica.

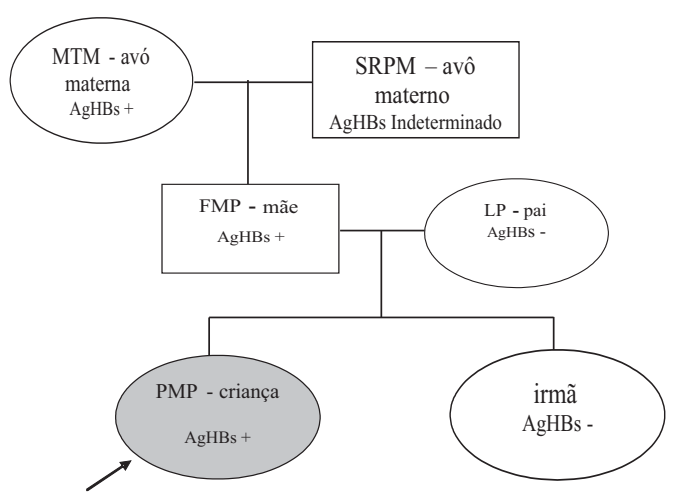

*A seta no heredrograma indica o primeiro caso notificado no núcleo familiar.

Figura 1 - Heredrograma do núcleo familiar do caso clínico de transmissão vertical de hepatite B. Florianópolis-SC.

\section{RESULTADOS}

Ressaltamos que, o quadro assintomático da doença é causa freqüente de disseminação do HBV. Destes, somente 30\% dos indivíduos que desenvolvem a doença apresentam icterícia e aproximadamente 5\% a $10 \%$ dos indivíduos infectados cronificam ${ }^{(3)}$.

A transmissão do HBV da mãe portadora para seu filho pode ocorrer no período gestacional. Neste caso, evidenciamos a importância do rastreamento do vírus da hepatite $\mathrm{B}$ durante o pré-natal, como uma das estratégias de prevenção da transmissão vertical.
Entretanto, a exposição perinatal é o modo mais eficiente de transmissão, podendo acometer 65 a $93 \%$ dos recém nascidos ${ }^{(12)}$. Esse mecanismo de transmissão ocorre por uma maior exposição mucocutânea da criança ao sangue ou secreção cérvico-vaginal materna. A descrição deste estudo mostra a alta prevalência da doença durante a gestação e parto, já que três gerações da família se contaminaram, provavelmente pela transmissão vertical, sendo que estas pessoas terão cerca de $90 \%$ de chances de cronificação e de hepatopatia crônica. Isso porque, cerca de metade dos casos crônicos evoluem para doença hepática avançada (cirrose e carcinoma hepatocelular) $)^{(3,13)}$.

Salientamos ainda que, essa transmissão pode ser evitada pelo uso de imunoglobulina anti-VHB (IGHB). Desta forma, para recém-nascidos de mães portadoras do HBV é obrigatório o uso da vacina contra o vírus associada ao uso da Imunoglobulina Humana Hiperimune contra o HBV (IGHB). Maior eficácia na profilaxia é obtida com o uso precoce, dentro de 12 horas, após o nascimento. Assim, é imprescindível a administração da IGHB e da vacina contra o VHB, logo após o parto ${ }^{(14)}$. A eficácia dessa conduta é de $95 \%$ e elimina o eventual risco de transmissão pelo leite materno ${ }^{(15)}$.

Evidenciamos também, a necessidade de ampliação do esquema vacinal contra hepatite B nas áreas de média e de alta endemicidade, já que a constante migração de outros estados e regiões para Santa Catarina, pode ser indicativa de uma onda epidêmica de hepatite $B$ nesse estado, o que altera o perfil epidemiológico da doença nos últimos anos.

Embora toda pessoa possa prevenir-se desta doença com a vacina, o Ministério da Saúde recomenda sua aplicação em crianças menores de um ano até 19 anos 11 meses e 29 dias e adultos que compõem o grupo de risco, como profissionais da saúde, policiais, integrantes de equipes de resgate, carcereiros e outros que tenham contato com sangue e secreções corporais ${ }^{(16)}$.

Neste estudo de caso, algumas das ações de Vigilância Epidemiológica realizadas foram: 1) Orientação quanto a vacinação do pai do caso (LP), já que a irmã havia recebido imunoglobulina na maternidade nas primeiras vinte quatro horas e a $1^{\mathrm{a}}$ dose contra hepatite B; 2) O caso (PMP) e sua mãe FMP, como tiveram marcadores sorológicos de VHB iguais na amostra de controle de seis meses, foram encaminhadas para acompanhamento com 
infectologista da rede básica de saúde do município de Florianópolis; 3) Encaminhamento para seu município de origem (oeste de SC) de uma cópia da ficha de investigação epidemiológica dos avós maternos MTM e SRPM, a fim de que fosse dado encaminhamento na investigação; 4) Orientação aos pais (LP e FMP) para uso de preservativos durante as relações sexuais e sobre as formas de contágio da doença; 5) Ênfase junto às unidades de saúde sobre a vacinação contra hepatite $B$, conforme idade e exposição a situação de risco, de acordo com o Manual de Normas e Procedimentos do Programa Nacional de Imunização (PNI); 6) Contato com a equipe de PSF da área de abrangência da família para monitoramento dos casos.

Salientamos a importância da investigação epidemiológica, quando vinculada às atividades de sistemas específicos de vigilância para a identificação de fatores e situações de risco, onde as ações de promoção e prevenção devem ser aplicadas.

A Vigilância em Saúde, tendo no seu contexto inserido a Vigilância Epidemiológica, tem como importante aliado, as Equipes de Saúde da Família. Possui em parceria com os Centros de Saúde a coresponsabilidade de realizar rastreamento e monitoramento de novos portadores da doença, aliandose aos níveis secundários da saúde, como os centros de referência para patologias específicas.

A participação da Enfermagem na Vigilância Epidemiológica na fase pré-diagnóstica compreende a coleta de informações que podem auxiliar na detecção dos casos confirmados, além de orientações e coleta de materiais para a realização de exames. Na visita domiciliar investiga-se a presença de sinais e sintomas da doença, a história de contato, a existência de vulnerabilidade ao agravo em foco, a história pregressa da doença infecciosa, os tratamentos realizados e as pessoas com quem o doente convive. A atuação da enfermagem também é fundamental quando a doença exige um tratamento prolongado, ou adoção de novos hábitos e comportamentos, visando à prevenção de intercorrências que resultem no atraso ou impeçam a recuperação do paciente ${ }^{(16)}$.

\section{CONSIDERAÇÕES FINAIS}

Geralmente os serviços de saúde pouco têm dispensado atenção e valorização do diagnóstico do vírus da hepatite B em gestantes, visando de forma ampla o controle da disseminação da doença de modo vertical. Pois, o teste diagnóstico da doença apesar de sua recomendação estrita durante o Pré-Natal, ainda não é obedecido com rigor por parte de alguns profissionais responsáveis pela sua solicitação.

Na transmissão vertical, a enfermagem pode prestar uma assistência qualificada elencando vários cuidados, que abordem desde a prevenção e promoção, até a recuperação e reabilitação da saúde. A deficiência destas ações pode acarretar em aumento significativo do número de recém-nascidos portadores da doença, com a agravante de não terem o diagnóstico precoce, tornando-se assim, portadores crônicos da doença. A sensibilização dos grupos enfatizados pelo Ministério da Saúde para recebimento da vacinação contra Hepatite B também é importante, já que há estudos que referenciam a resposta imunológica e a soroproteção aos indivíduos ${ }^{(17)}$. A enfermagem além das ações de prestações de cuidado deve ter atitude ética e responsabilidade social, um compromisso também legal e profissional com a dignidade humana, por estar habilitada técnica e cientificamente para a função de cuidar ${ }^{(18)}$.

De modo geral, é função da Vigilância Epidemiológica e das equipes de PSF adotar medidas de controle específicas para hepatite. Para isso, faz-se necessário o esclarecimento da comunidade quanto às formas de transmissão, tratamento e prevenção das hepatites virais.

No estudo que por ora apresentamos, desenvolveu-se um conjunto de atividades denominadas atividades básicas de vigilância epidemiológica e que são: a definição dos fatos ou eventos que se quer observar; a produção e coleta dos dados necessários; sua consolidação e análise para produção das informações pertinentes; a tomada de decisão e orientação de ações de controle com base nas informações obtidas; a divulgação e discussão das informações produzidas pelo sistema e das ações de controle efetuadas e seus resultados ${ }^{(11)}$.

Entendemos nossas limitações ao abordar o tema, mas esperamos que este trabalho incite em outros profissionais o interesse e a prática destas ações importantes.

Na tentativa de desenvolver ações sistemáticas para prevenção e controle da transmissão vertical da hepatite $B$, salientamos a maior visibilidade a esta situação, permitindo o exercício da cidadania. Dessa forma, possibilitamos que a sociedade atue também, na construção de um sistema de vigilância à saúde, 
estando atenta aos eventos que ocorrem e agindo para o controle destes.

\section{REFERÊNCIAS}

1. Figueiredo G. Programa de hepatites virais. [acesso em 200824 de Abril]. Disponível em: www.portal.saude.gov.br/portal/svs.

2. Souto FJD, Yonamine F, Fontes CJF, Santos DRL, Oliveira SS, Gaspar AMC. Prevalência da hepatite B em área rural de município hiperendemico na Amazônia Mato - Grossence: situação epidemiológica. Rev do Sistema Único de Saúde do Brasil: Epidemiologia e Serviços de Saúde. 2004; 13(2).

3. Ministério da Saúde (BR). Programa nacional de hepatites virais. Hepatites virais: O Brasil está atento. Brasília: Ministério da Saúde; 2003.

4. Dutra RL, Haas, P. Hepatite B no Estado de Santa Catarina. News Lab. 1999;7(35):102-4.

5. Secretaria de Vigilância Epidemiológica de Santa Catarina. Sistema de Informações de Agravos de Notificação. Florianópolis: Secretaria de Vigilância Epidemiológica de Santa Catarina; 2002.

6. Vigilância Municipal de Florianópolis. Boletim de Notificação dos casos de hepatites virais no Estado de Santa Catarina. Florianópolis: Vigilância Municipal de Florianópolis; 2002.

7. Ministério da Saúde (BR). Secretaria de Vigilância em Saúde. Departamento de Vigilância Epidemiológica. Doenças Infecciosas e Parasitárias: Guia de Bolso. Brasília: Ministério da Saúde; 2004.

8. Tudo o que você precisa saber sobre hepatites virais. Rio de Janeiro: Gráfica MCE; 2006.

9. Comissão para as Doenças Infecciosas da Academia Americana de Pediatria. Imunização de adolescentes: recomendações. Pediatrics. 1997;1(7):535-46.

10. Arraes LC, Sampaio AS, Barreto S, Guilherme MAS, Lorenzato F. Prevalência de hepatite B em parturientes e perfil sorológico perinatal. RBGO 2003; 25(8):571-6.

11. Ministério da Saúde (BR). Agencia Nacional de Vigilância Sanitária. Curso Básico de Controle de Infecção Hospitalar. Caderno A. Epidemiologia para o controle de infecção hospitalar. Brasília: Ministério da Saúde; 2000.
12. Mussi-Pinhata MM. Imunogenecidade da vacina contra hepatite B iniciada precocemente em pré - termos: implicações para a prevenção. J Ped. 2004;80(2):90-2.

13. Gimeniz GMT, Gonçalves VS, Veríssimo, OMI. Cuidados ao binômio mãe-filho em decorrência de Hepatite B. Rev Panam Salud Publ. 2004; 14(2).

14. Lamounier JA, Moulin ZS, Xavier CC. Recomendações quanto à amamentação na vigência de infecção materna. J Ped. 2004;80(5):181-88.

15. Sociedade Brasileira de Pediatria. Documento Científico Gastroenterologia da Sociedade Brasileira de Pediatria. Rio de Janeiro; 2004.

16. Mariano, AF, Bento, DG. A Rede de Assistência e o Auto-Cuidado dos Portadores de Hepatite B na Regional Sul do Município de Florianópolis [trabalho de conclusão de curso]. Biguaçu (SC): Universidade do Vale do Itajaí; 2005.

17 Martins RM, Bensabath G, Arraes LC, Barbosa, GG, Oliveira MLA, Camacho LAB. Estudo Multicêntrico de imunogenicidade e reatogenicidade de vacinas contra hepatite B: informe preliminar. Rev do Sistema Único de Saúde do Brasil: Epidemiologia e Serviços de Saúde. 2003;12(3).

18 Kloch P, Rodrigues ACRL, Backes DS, Erdmann AL. O cuidado como produto de múltiplas interações humanas: "Importando-se com o Outro". Cogitare Enferm. 2007;12(4):452-9. 